\title{
IDENTIDADES E MEMÓRIAS: UM ESTUDO ACERCA DA CONSTRUÇÃO DA IDENTIDADE PROFISSIONAL DO ASSISTENTE SOCIAL
}

\author{
Luiza Bettanzos ${ }^{1}$ \\ Ana Patrícia Barbosa (Orientação) ${ }^{2}$
}

\section{Introdução}

O presente trabalho é resultado da articulação das vivências desenvolvidas a partir das experiências no Estágio Obrigatório em SS e dos conteúdos apreendidos durante a formação em SS. O tema deste estudo versa sobre a Identidade profissional, sendo a sua delimitação a identidade profissional e sua interface com o processo de trabalho do assistente social no Centro Social e Educacional Assunta Marchetti. Trata-se de uma instituição do Terceiro Setor que se localiza no quadrante nordeste do município de Canoas (Rio Grande do Sul), na R. Onorino Andreazza, número 82, bairro Olaria, e seu atendimento corresponde aos bairros Estância Velha, Olaria e Guajuviras.

O objetivo deste estudo é refletir sobre a Identidade Profissional no processo de trabalho do assistente social, vivenciado durante o estágio obrigatório no Serviço Social.

A escolha de refletir acerca da identidade profissional do assistente social em relação ao seu processo de trabalho se deu após aproximação com o campo de Estágio Obrigatório em Serviço Social, identificando como demanda as desarticulações presentes nesse processo e sua relação com a Questão Social. A temática inicialmente se justifica devido ao fato da constatação empírica sobre a forma como a profissão traz consigo marcas de uma identidade atribuída.

Entendendo as desarticulações como resultantes da contradição, foi possível identificar como elas se expressam no processo de trabalho, e a partir disso foi possível perceber a categoria identidade a ser fortalecida dentro desse espaço. A identidade profissional é construída dialeticamente e por isso precisa ser constantemente reapropriada dentro do contexto da sociedade capitalista. Nesse sentido, a necessidade

\footnotetext{
${ }^{1}$ Universidade Luterana do Brasil. E-mail comerlatoluiza@gmail.com. ORCID: https://orcid.org/00000002-9155-0854

${ }^{2}$ Universidade Luterana do Brasil. E-mail ana.barbosa@ubra.br. ORCID: https://orcid.org/0000-00021154-6047
} 
de refletir sobre esse tema extrapola a abordagem dessa intervenção, dizendo respeito a uma necessidade da profissão como um todo.

A relevância de aprofundamento dessa temática se deu no sentido de discutir de maneira contínua a profissão, sua identidade construída em especial no contexto atual, marcado por profundas mudanças sociais. O presente trabalho emerge neste cenário, no sentido de contribuir com reflexões relacionadas a essa identidade que se constrói na dinâmica da sociedade capitalista.

A partir da observação de campo, foi identificado que a Identidade é uma categoria que necessita ser constantemente reapropriada pela profissão, não apenas por seu caráter dinâmico, mas também pela necessidade de firmar seu compromisso nos antagonismos da sociedade de classe. Esse entendimento parte da compreensão do Serviço Social enquanto profissão inserida na divisão sócio técnica do trabalho, ou seja, das suas condições enquanto trabalho.

A intervenção realizada em Estágio Obrigatório foi feita a partir de uma abordagem grupal, onde, com o intuito de fortalecer o arsenal teórico metodológico, foi feito um grupo de estudos sobre temas presentes no cotidiano da equipe técnica daquele espaço, fazendo uma reaproximação dos fundamentos teórico metodológicos profissionais, das demandas de trabalho do Centro Social e Educacional Assunta Marchetti, e do instrumento capacitação continuada para o fortalecimento da própria Identidade.

As políticas sociais que se apresentam no campo de Estágio são a PNAS (Política Nacional de assistência social) e a articulação com o CNAS (Conselho Nacional de Assistência Social) que se tornaram parte do trabalho do Serviço Social na instituição a partir de 2015, além da articulação das legislações que asseguram a profissão, como Lei de Regulamentação da profissão (8.742/93), o Código de Ética do Assistente Social (Lei 8662/93) e o Projeto Ético Político do Serviço Social.

A metodologia utilizada neste estudo tem por base o relato da experiência vivida no campo de estágio articulada a pesquisa bibliográfica. O presente artigo está estruturado em três tópicos. No primeiro apresenta-se uma discussão sobre o Terceiro Setor e a Questão Social, em especial no que se refere aos desafios profissionais na materialização do Projeto Ético Político do Serviço Social.

No tópico 2 discorre-se sobre as políticas sociais e sua interface com a identidade profissional, dando ênfase à reflexão sobre o lugar da memória e da história 
na trajetória do Serviço Social. Por fim, no tópico terceiro apresenta-se o processo de trabalho, a partir do projeto de intervenção desenvolvido no campo de estágio, dando ênfase ao objeto, meios e o produto da intervenção.

\section{Metodologia}

Começaremos por conceituar metodologia, conforme Minayo (2010, p. 22), a metodologia é "o caminho e o instrumental próprios de abordagem da realidade". Sob essa perspectiva, o presente estudo retrata um relato de experiência.

Essa produção do trabalho final em Serviço Social contou com a articulação dos conhecimentos apreendidos durante a formação acadêmica com a intervenção desenvolvida no campo de estágio, embasou-se pelas dimensões teórico-metodológica, ético-política e técnico-operativa. Em termos teórico-metodológico, este estudo respaldou-se no Materialismo Histórico e Dialético e as categorias do método dialético: historicidade, totalidade e contradição, que possibilitou desvelar a realidade social em que os sujeitos encontram-se inseridos, buscando compreender as desarticulações entre o trabalho de gestão institucional e o processo de trabalho do assistente social no Centro Social e Educacional Assunta Marchetti, identificado no Projeto de Intervenção Fortalecimento da Identidade do Serviço Social, onde através de um grupo de estudos realizado com a equipe técnica, dando ênfase na dimensão teórico metodológico do Serviço Social, foram revisitados temas como Questão Social, terceiro setor e identidade profissional.

O estudo de campo necessário para a realização deste trabalho foi feito entre os anos de 2019 e 2020, através das disciplinas de Estágio Obrigatório em Serviço Social I e II. O estágio foi realizado junto com a coordenação de Serviço Social do Centro Social e Educacional Assunta Marchetti.

A intervenção no campo de estágio, foi planejada a partir da análise institucional, com o objetivo de reconhecer os elementos que incidem sobre a sua dinâmica; Identificar e tematizar o objeto de trabalho da instituição e do Serviço Social; identificar e analisar os elementos que compõem o processo de trabalho do assistente social; planejar a intervenção a ser desenvolvida na segunda etapa do estágio, através do mapeamento das necessidades de intervenção profissional e, por fim, elaborar o projeto de intervenção a ser implementado e executado na instituição. 
Metodologicamente, sob o ponto de vista da escolha das técnicas e procedimentos foram utilizados os instrumentos: foram realizadas acolhidas sociais acolhida coletiva, diário de campo, observação, registros, análise institucional, visitas de campo, acompanhamento da gestão e pesquisa no acervo documental da instituição. A abordagem desenvolvida no processo de intervenção foi a de grupo, com a participação de 4 estagiárias de Serviço Social e a assistente social supervisora, sendo o produto materializado, resultante desse grupo, um marca páginas. Além da pesquisa de campo, esse estudo usa de pesquisa bibliográfica, essa última classificada por Gil (2010) como: aquela elaborada por material bibliográfico já publicado referente ao pensamento de determinado autor, que visa a analisar as posições de diversas áreas com relação ao tema.

Sendo estes os instrumentos que propiciaram o aprofundamento teórico que norteia esse estudo, para sua fundamentação teórica e discussão de novas categorias que surgiram ao longo da organização deste artigo. No âmbito da dimensão ético política, foram priorizados os princípios éticos, em consonância com o Código de Ética do/a Assistente Social.

\section{Terceiro Setor e Questão Social: Desafios Profissionais na Materialização do Projeto Ético Político}

O objetivo deste estudo é refletir acerca da Questão Social, com o enfoque de como vem sendo feito seu enfrentamento historicamente e a articulação que ela possui com o terceiro setor, bem como a conceituação teórica do significado de terceiro setor e os desdobramentos dessa categoria na realidade social.

O Serviço Social tem como objeto genérico de trabalho a Questão Social, através de suas mais diversas expressões, tais como o desemprego, a desigualdade social e a pobreza que se manifestam na vida dos sujeitos. As condições que originam essa categoria estão intrinsecamente relacionadas ao sistema de organização econômica vigente a partir do século XIV. Para caracterizar Questão Social, Carvalho e Iamamoto argumentam

[...] não é senão as expressões do processo de formação e desenvolvimento da classe operária e de seu ingresso no cenário político da sociedade, exigindo seu reconhecimento como classe por parte do empresariado e do Estado. É a manifestação, no cotidiano da vida social, da contradição entre o 
proletariado e a burguesia, a qual passa a exigir outros tipos de intervenção mais além da caridade e repressão. (Carvalho e Iamamoto, 1983: 77).

É, portanto, a contradição presente entre capital e trabalho que se multifaceta em expressões como o desemprego, a miséria, a vulnerabilidade social, entre outras demandas que fazem parte do cotidiano de trabalho dos assistentes sociais. A definição que melhor abrange essa produção está relacionada às consequências da apropriação privativa do trabalho socialmente distribuído, nessa esteira de raciocínio Iamamoto escreve:

\begin{abstract}
A questão social diz respeito ao conjunto das expressões das desigualdades sociais engendradas na sociedade capitalista madura, impensáveis sem a intermediação do Estado. Tem sua gênese no caráter coletivo da produção, contraposto à apropriação privada da própria atividade humana -- o trabalho - das condições necessárias a sua realização, assim como de seus frutos. É indissociável da emergência do "trabalhador livre", que depende da venda de sua força de trabalho como meio de satisfação de suas necessidades vitais." (Iamamoto, 2001 a:17a).
\end{abstract}

Ainda sobre o conceito de Questão Social, o processo ao qual ela se apresenta [...] é denso de conformismos e resistências, forjados ante as desigualdades, expressando a consciência e a luta pelo reconhecimento dos direitos sociais e políticos de todos os indivíduos sociais (IAMAMOTO 2001, p.17b), com isso podemos afirmar que Questão Social também é resistência, pois se forja perante lutas pela superação da exploração de classe.

Sobre o conceito de luta de classes, Marx escreve que "a história de toda sociedade até hoje é a história de lutas de classes" (Marx, 1996: 66). A burguesia e o Estado se articulam na contenção a essa ameaça de rompimento do sistema de classes, lembremos que na sociedade burguesa "as ideias da classe dominante são, em todas as épocas, as ideias dominantes". e ainda, “[...] todas as classes que aspiram ao domínio [...] têm primeiro de conquistar o poder político". (Marx, 1845: 96). Portanto, são expressivas as iniciativas tomadas pelo Estado a fim de conter os esforços das massas proletárias, podendo se expressar através da coerção, políticas e meios de conciliação de classe.

A emergência do terceiro setor se dá a partir das expressões da Questão Social já antes comentadas, mas o terceiro setor como resposta não deixa de demonstrar expressões do controle do Estado, uma vez que carregam em si a ideia de conciliação de classes. A categoria terceiro setor é conceituada a partir de Fischer: 
Terceiro Setor é a denominação adotada para o espaço composto por organizações privadas, sem fins lucrativos, cuja atuação é dirigida a finalidades coletivas ou públicas. Sua presença no cenário brasileiro é ampla e diversificada. Sendo que essa diversidade é resultante da riqueza e pluralidade da sociedade brasileira e dos diferentes marcos históricos que definiram os arranjos institucionais nas relações entre o Estado e o Mercado. (Fischer, 2002:45).

O Terceiro Setor nasce como resposta alternativa desvinculada ao poder público de combate às expressões da questão social. Partimos por isso do ponto que a sociedade se divide em setores sendo o Primeiro Setor o Estado, o Segundo Setor o Mercado, e o Terceiro Setor a sociedade civil organizada, Costa (2003). Ainda sobre o conceito de Terceiro Setor, Andrade argumenta que:

A auto desresponsabilização do Estado diante das expressões da questão social cria esse novo padrão de resposta, de enfrentamento ou gestão da questão social por parte do Estado capitalista, caracterizado como um modelo de gestão social em que o Estado se afasta da execução direta e desenvolve parcerias com as organizações sociais para a realização de ações sociais. (Andrade, 2015:325).

As articulações da sociedade civil organizada são responsáveis por firmar acordos entre sociedade e Estado, mas uma vez burocratizadas por ele, passam a fazer parte dos consensos do direito burguês. A terceirização das responsabilidades de ordem social por parte do Estado não funciona apenas como uma transferência de responsabilidade, mas também como um amortecedor das lutas políticas que nascem a partir da organização social.

É recente na verdade o acúmulo de legislações que regulamentam o trabalho prestado por instituições de terceiro setor, exemplo delas a PNAS (2004) e a LOAS (Lei orgânica de assistência social, 1993) entre outras políticas específicas.

Por conta do esvaziamento político por parte do Estado do que se entende por terceiro setor, e também das diferentes formas de organização da sociedade civil, muitas ações promovidas se baseiam em filantropia e caridade, retomando discussões que circundam as origens do Serviço Social.

$\mathrm{Na}$ particularidade do Centro Social e Educacional Assunta Marchetti, organização de terceiro setor, se localiza no bairro Olaria, e corresponde ao atendimento dos bairros Estância Velha, Guajuviras e Olaria. São muitas as expressões da Questão Social que perpassam a vida dos sujeitos que vivem nesta região. Em resposta a problemática das expressões da Questão Social no território, o Centro Social vem a 
mais de 31 anos ofertando serviços que contemplam essas demandas. A instituição é mantida pela ordem de irmãs scalabrinianas, e por isso possui um viés messiânico em suas atividades ao lidar com as expressões da Questão Social.

A instituição tem por objetivo a promoção e autonomia humana, as expressões causadas pela relação entre capital e trabalho não se limitam ao que chega à sala do Serviço Social, mas dizem respeito também a essas incongruências de um trabalho despolitizado e precarizado.

A precarização do trabalho dos assistentes sociais na realidade das instituições do terceiro setor, e como exemplo no campo observado, se demonstra através da alta demanda de trabalho e múltiplas funções exercidas por um profissional de Serviço Social, os inúmeros desdobramentos que não são apenas de ordem técnica e acabam por se tornarem responsabilidade desse profissional, e as diversas atividades que na ausência de recurso para contratação de profissionais, ou mesmo a não valorização desse conhecimento técnico, são desenvolvidas por voluntários.

Por muitos anos o trabalho da instituição se orientou por doação religiosa ao qual as irmãs scalabrinianas respondiam a diversas demandas de ordem técnica, foi somente em 2015, com a chegada de uma assistente social em turno integral que a o Centro Social passou a fazer parte das reuniões do CNAS (Conselho Nacional de Assistência Social) e introduziu a PNAS no seu cotidiano.

É evidente que o trabalho desenvolvido não tem por objetivo a precarização de si mesmo, e que a intenção desde o início tanto das irmãs quanto da mantenedora que dão continuidade a esse projeto não é a de deturpar o significado da identidade construída do Serviço Social (Martinelli,2003) mas que essa deturpação é uma condição da disputa de projetos societários dessa sociedade.

Sobre essa disputa de projetos societários, é importante ressaltar que o antagonismo entre capital e trabalho gera diferentes interesses de classe, e os interesses das lutas proletárias apontam para um rompimento da ordem de exploração, por isso um novo projeto de sociedade. E como são as ideias da classe dominante são o consenso estabelecido (Marx1845) toda produção de pensamento dessa sociedade não é neutra, sobre a dominação do pensamento Martins escreve:

Entendo que o modo capitalista de produção, na sua acepção clássica, é também um modo capitalista de pensar e deste não se separa (...) enquanto modo de produção de ideias, marca tanto o senso comum quanto o conhecimento científico. Define a produção de diferentes modalidades necessárias à produção de mercadorias em 
condições de exploração capitalista, da coisificação das relações sociais e da desumanização do homem. (Martins, 1978,: 6-7).

A identidade do Serviço Social foi forjada a partir de lutas dentro da própria categoria profissional e se faz compreender a razão a qual a profissão encontra dificuldade na divisão sociotécnica do trabalho, porque a disputa de projetos não é uma realidade individual desse ou de outro espaço sócio ocupacional, lutar a fim de uma sociedade que rompa com a exploração é na verdade desfazer consensos impostos, mascarados de realidade.

No tópico que segue será feita uma discussão acerca das políticas sociais, da identidade profissional e uma breve aproximação do Centro Social e Educacional Assunta Marchetti.

\section{Políticas Sociais e Identidade Profissional: O Lugar da História e da Memória na Trajetória do Serviço Social}

Esse tópico tem como objetivo a discussão sobre diferentes perspectivas do conceito de políticas sociais, sua relação com a identidade profissional, o decorrer da construção dessa identidade e o papel da memória no Serviço Social nesse desenvolvimento.

Fazendo uma breve retomada do tópico anterior, o Terceiro Setor representa a ausência do Estado em relação às expressões da Questão Social, não se trata de uma incapacidade, e sim de uma ausência voluntária em relação a lida com a Questão Social, se dando em decorrência de medidas de redução da proteção por parte do Estado, resultado de correntes teóricas liberais ${ }^{3}$.

As políticas sociais também fazem parte das estratégias de lidar com a Questão Social, mas de uma resposta que parte do Estado. Para uma discussão mais detalhada apresento o conceito de Políticas Sociais a partir de Franco:

a intervenção na realidade, por meio de ações (se possível, coordenadas) que destinam recursos escassos para aumentar o bem-estar da população em seu conjunto, o que em geral se atinge (principalmente) diminuindo os setores que vivem em situação de pobreza (Franco, 1988: 65).

\footnotetext{
${ }^{3}$ De acordo com Behring: "O liberalismo alimentado pelas teses de David Ricardo e sobretudo de Adam Smith (2003), que formula a justificativa econômica para a necessária e incessante busca do interesse individual, introduz a tese que vai se cristalizar como um fio condutor da ação do Estado LIberal: cada indivíduo agindo em seu próprio interesse econômico. “(2009, p.56).
} 
A ideia de "bem comum" é insuficiente para descrever as articulações que o Estado desenvolve de enfrentamento às consequências da contradição, porque os interesses da classe dominante são antagônicos aos interesses das classes subalternas. Nesse modo de produção é insustentável a redistribuição de qualquer tipo de recurso, na verdade é justamente a apropriação privada da riqueza socialmente produzida que caracteriza como se dão as relações de produção nessa sociedade. Ainda sobre as políticas sociais Behring salienta:

\begin{abstract}
Uma interpretação da questão social como elemento constitutivo da relação entre o Serviço Social e a realidade, tendo como mediação as estratégias de enfrentamento adotadas pelo Estado e pelas classes, o que envolve as políticas sociais como elemento central [...] o debate deve incorporar, necessariamente, os componentes de resistência e de ruptura presentes na constituição de formas de enfrentamento da questão social, ou seja, esse conceito está impregnado de luta de classes (Behring 2009.:55).
\end{abstract}

As políticas nascem, portanto, principalmente após a revolução industrial, onde a condição de venda da mão de obra expõe aos trabalhadores intensas cargas horárias de trabalho. Por mais imprecisa que possa parecer a definição dessa categoria, é conveniente que se entenda de forma ampla sua definição, porque nem no decorrer de sua própria constituição as políticas sociais possuíram o mesmo caráter.

Não se pode precisar exatamente quando nasceram as políticas sociais. Quanto à protoformas que deram origem a ela, como um exemplo, a constituição da lei dos pobres (1531- 1601) ${ }^{4}$, um marco em relação a conquista da população vulnerável, historicamente, era destinada aos pobres que tinham condições de vender sua força de trabalho, e ainda, não poderiam ter poder de escolha em relação a esse trabalho desenvolvido, demonstrando como se davam as formas de lidar com a pobreza na época, como outras políticas da antiguidade continha um caráter de controle, vigilância e compensação.

$\mathrm{O}$ advento do liberalismo que vai de meados do século XIX ao século XX (BEHRING 2009) e posteriormente do neoliberalismo são novos paradigmas que se apresentam para as políticas sociais, porque colocam em questão o papel que o estado assume perante ao enfrentamento da Questão Social, entretanto voltamos a discutir a

\footnotetext{
${ }^{4}$ Nas palavras de Behring “As legislações promulgadas até 1795 tinham como função principal manter a ordem de castas e impedir a livre circulação da força de trabalho [...] o princípio estruturador dessas leis era obrigar o exercício do trabalho a todos que apresentassem condições de trabalhar, e as ações assistenciais previstas tinham o objetivo de induzir o trabalhador a se manter por meio de seu trabalho." (2009, p. 48).
} 
origem das políticas sociais relacionadas à filantropia e gestadas na igreja católica, pois procura-se destacar o surgimento do Serviço Social como executor das políticas sociais, e para isso se faz uso da categoria identidade, definida por Martinelli como:

[...] a identidade da profissão em si mesma considerada como elemento definidor de sua participação na divisão do trabalho e na totalidade do processo social. Portanto mais do que uma categoria filosófica, dotada de estatuto lógico e ontológico, a identidade profissional está sendo pensada dialeticamente, como uma categoria política e sócio-histórica que se constrói na trama das relações sociais, no espaço social mais amplo da luta de classes e das contradições que a engendram e são por elas engendradas. (Martinelli, 2003:17).

E é a partir das relações sociais que se constroem as identidades, e por isso seguem um movimento dialético, tanto ao que diz respeito de uma identidade coletiva quanto à identidade individual. O Serviço Social nasce a partir da necessidade de um profissional que executasse as medidas de controle decorrentes das expressões da Questão Social. A profissão é gestada no seio da igreja católica, sendo resultado da junção da tríade igreja, burguesia e Estado, articulados objetivando medidas de contenção que não ameaçassem o Status Quo, em outras palavras, defendendo seus interesses enquanto classe.

A identidade primeira, sendo alienada, possuía uma perspectiva de realidade fragmentada, pois não compreendia nem a si mesmo enquanto profissão fazendo parte da divisão sócio técnica do trabalho, e culpabilizando os sujeitos pelas suas situações e seus sofrimentos, individualizando situações de maior complexidade social. Noções de identidade essas que partem de Martinelli (2003). Após o movimento de reconceituação do Serviço Social, vivido entre 1965 e a segunda metade de 1970 no Brasil, os profissionais passaram a criticar a razão de existência profissional, tendo em vista outra abordagem teórica - o materialismo histórico.

Seguindo a perspectiva materialista profissional, novos documentos, construídos pela categoria profissional, passam a assegurar o trabalho profissional, tais como a Lei de Regulamentação da profissão $(8.742 / 93)^{5}$, o Código de Ética do Assistente Social

\footnotetext{
${ }^{5}$ Lei aprovada em 13 de março de 1993, regulamenta a profissão, permitiu que passasse a ser necessária a formação em ensino superior para o exercício do trabalho profissional e aponta no seu artigo 5o as competências privativas da profissão (CFESS, 2011).
} 
(Lei 8662/93) ${ }^{6}$ e o Projeto Ético Político do Serviço Social ${ }^{7}$. A respeito do projeto ético político, Iamamoto refere:

[...] Seu potencial renovador da profissão na afirmação dos direitos sociais dos cidadãos e cidadãs, na atenção e no respeito às suas necessidades e interesses que, por inúmeras mediações, se transmutam em demandas sociais e profissionais [...] avançar uma legitimação da profissão na sociedade, na apropriação e ampliação dos espaços ocupacionais, reforçando a nossa identidade profissional. O desafio maior é, pois, traduzir o projeto éticopolítico em realização efetiva no âmbito das condições em que se realiza o trabalho do assistente social. (Iamamoto, 2001:36)

O assistente social, sujeito à condição de assalariado dada sua inserção na divisão técnica do trabalho, é sujeito dos movimentos do capital. Tanto onde irá intervir quanto a sua própria intervenção atenderá a essa demanda. Cabe aos profissionais, tendo em vista os limites que o assujeitamento indica, trabalharem nas estratégias para a construção de uma nova sociedade.

Toda construção da trajetória da profissão é o que hoje alicerça o Serviço Social ao lado da classe trabalhadora e se compreendendo como tal, também é o que torna possível apoiar-se ao interesse de exercer a intencionalidade em seu trabalho, bem como o entendimento da centralidade fundamental que as lutas políticas representam para essa categoria.

A esse ponto já é possível vislumbrar a importância que a memória constitui nessa realidade, parafraseando Martinelli (2019) a identidade consolidada da profissão no Brasil se formou através do trabalho de diversos profissionais nesses 80 anos de história, pesquisar o passado permite fazer descobertas quanto a esse trabalho e por isso é indispensável na compreensão desse amadurecimento. Utilizemos a conceituação de memória de Halbwachs para uma maior aproximação dessa categoria:

\footnotetext{
${ }^{6}$ Em seus 11 princípios estabelece o compromisso ético-político do Serviço Social, aponta as normativas referentes a esse trabalho e o horizonte das ações profissionais, ainda sobre o Código de Ética Profissional é “a materialização do Projeto Ético-Político profissional construído nos últimos 30 anos no seio da categoria, haja vista que formulados para dar sustentação legal ao exercício profissional dos/as assistentes sociais, mas que não se restringem a essa dimensão. Pelo contrário, fortalecem e respaldam as ações profissionais na direção de um projeto em defesa dos interesses da classe trabalhadora e que se articula com outros sujeitos sociais na construção de uma sociedade anticapitalista." (CFESS, 2011, p.14).

${ }^{7}$ É um marco na ruptura com o conservadorismo no interior da profissão, escrito a partir do Congresso da Virada em 1979, período em que o brasil passava pela redemocratização "construía-se um projeto profissional que, vinculado a um projeto social radicalmente democrático, redimensionava a inserção do Serviço Social na vida brasileira, compromissando-o com os interesses históricos da massa da população trabalhadora. $\mathrm{O}$ amadurecimento deste projeto profissional, mais as alterações ocorrentes na sociedade brasileira (com destaque para a ordenação jurídica consagrada na Constituição de 1988)" (CFESS, 2011, p.20).
} 
O processo social de reconstrução do passado vivido e experimentado por um determinado grupo, comunidade ou sociedade. Este passado vivido é distinto da história, a qual se refere mais a fatos e eventos registrados, como dados e feitos, independentemente destes terem sido sentidos e experimentados por alguém (Halbwachs, 1990: 2).

No contexto da retomada de memória, o Centro Social e Educacional Assunta Marchetti, enquanto instituição do terceiro setor, possui uma caminhada própria e marcada por ações que remetem a benevolência religiosa e a filantropia. Essas ações são compreensíveis dados os objetivos primeiros de ajuda e espiritualidade ${ }^{8}$, no território do quadrante nordeste de Canoas, ao qual se propunham, mas que no decorrer histórico dessa instituição e na medida em que ocorre o cruzamento com o Serviço Social essas respostas passam a se tornar insuficientes.

Abordar o papel da memória na constituição de instituições do terceiro setor não apresenta de maneira alguma um deslocamento da discussão proposta por Martinelli sobre a retomada da memória profissional, porque o terceiro setor é um espaço de inserção de assistentes sociais, e suas trajetórias relacionadas à benevolência da prática se interligam.

O Centro Social e Educacional Assunta Marchetti tem papel importante de referência da assistência (ou "ajuda" como é entendido no território) no quadrante nordeste do município de Canoas. Sendo um ponto de passagem para diversas famílias todos os dias em busca de subsídios básicos para sobrevivência (cestas básicas, doações de roupas, acesso a direitos sociais e outros).

Figura 1 - Desenho representando a casa das irmãs scalabrinianas

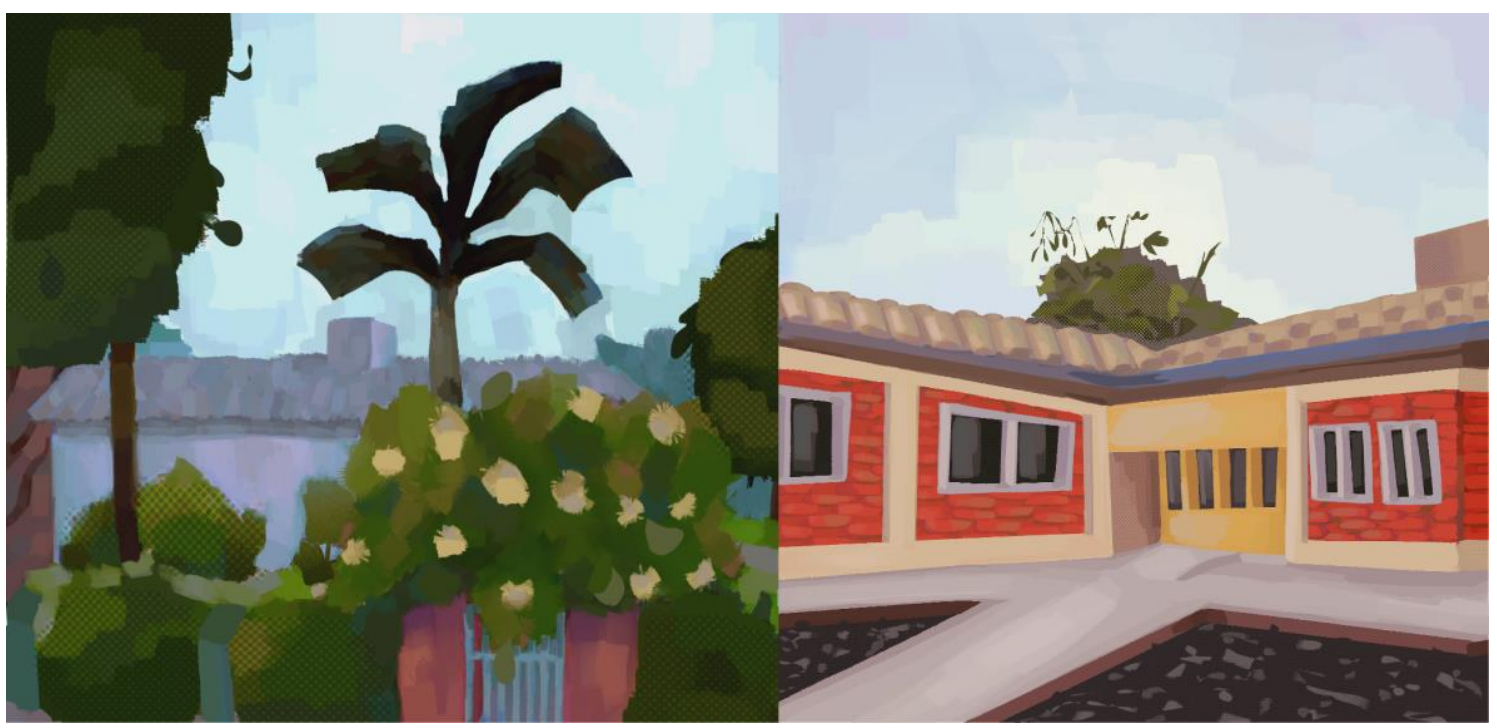

\footnotetext{
${ }^{8}$ Informação com base no endereço https://centro-socioeducacional-assunta-marchetti.webnode.com/.
} 
De acordo com estudo tanto de documentos institucionais ${ }^{9}$ quanto a partir de narrativas orais (Martinelli 2019) foi possível entender que até o ano de 2008 as atividades eram feitas esporadicamente, e que apesar da chegada das irmãs scalabrinianas no território em 1989, somente em 1995 as atividades começaram a ser desenvolvidas com famílias, no início somente seis famílias, na garagem da casa onde as irmãs se hospedavam. Essas atividades eram principalmente com intuito de prover recursos básicos, como cobertores e comida. Ressalta-se aqui a necessidade de escrever a memória oral na tentativa de não deixar que ela se perca com o passar dos anos, para Benjamin:

\begin{abstract}
A imagem autêntica do passado só aparece como um relâmpago. Imagem que apenas surge para eclipsar-se para sempre no instante seguinte. Aquela verdade imóvel, que fica lá à espera do pesquisador, não corresponde em nada a este conceito de verdade em matéria de história. É uma imagem única e insubstituível do passado, que desaparece com cada presente incapaz de se reconhecer visado por ela. (Benjamin, 2020:1524).
\end{abstract}

Na linha de raciocínio do autor, a história não se trata apenas de uma incansável busca de detalhes e datas mas de uma aproximação com as sensações, sentimentos e ideias dos sujeitos que vivenciaram a situação, por isso a memória tem o poder de comunicar muito mais sobre o contexto vivenciado do que apenas informações podem nos transmitir. Cabe por isso priorizar os relatos de trabalho e vida dos interlocutores desse espaço.

O entendimento da profissão de Serviço Social, tanto pela população atendida, quanto pela mantenedora contratante desse profissional, é de uma identidade que já foi rompida décadas atrás, no período de ruptura com correntes conservadoras do agir profissional, no contexto de redemocratização brasileira. Se faz necessário com isso situar a categoria identidade. De acordo com Martinelli (2003) a identidade pode ser definida como:

Sob o ponto de vista dialético, a identidade é uma categoria sócio histórica que pulsa com o tempo e com o movimento, a partir de determinações políticas, sociais, econômicas, históricas, culturais. Como categoria éticopolítica, cujo corolário natural é a consciência, a identidade constrói-se no fértil terreno da diferença, no interior de relações sociais antagônicas. (MartinellI, 2003:145-146).

\footnotetext{
${ }^{9}$ Principalmente em atas de trabalho a partir do ano de 1989 quando se iniciaram as atividades no território.
} 
As condições históricas necessárias e o caminhar dessa profissão é que podem definir sua identidade, identidade essa que é dinâmica e está sujeita ao movimento das forças sociais. Podemos dizer que essa nova face da profissão nasceu da necessidade de resposta ao que é afinal o Serviço Social, o que faz e em que intervém. Contudo, apesar de uma compreensão hegemônica de identidade na categoria profissional, não é necessariamente claro para as instituições contratantes ou os usuários atendidos. Por vezes nem mesmo o Estado deixa de atribuir políticas assistencialistas ao trabalho do Serviço Social.

O objeto de trabalho da intervenção desenvolvida seguiu se relacionando com as desarticulações entre o trabalho de gestão institucional e o processo de trabalho do assistente social. Sendo a Questão Social resultante da contradição entre capital e trabalho, a relação que se faz entre as desarticulações do processo de trabalho do Serviço Social nesse espaço assume duas faces, a primeira se refere ao projeto profissional, e a segunda se refere a força de trabalho como uma mercadoria, sobre projeto profissional, Netto (1999) define o como:

[...] são estruturas dinâmicas, respondendo às alterações no sistema de necessidades sociais sobre o qual a profissão opera, às transformações econômicas, históricas e culturais, ao desenvolvimento teórico e prático da própria profissão e, ademais, às mudanças na composição social do corpo profissional. (Netto, 1999: 3-5).

São os projetos profissionais que desenham o rumo que essa profissão deseja tomar, o atual projeto profissional se demonstra antagônico ao projeto societário em que encontra pois, em especial no Serviço Social a partir do materialismo dialético essa profissão busca romper com a sociedade de classes.

[...] este enfrentamento de projetos profissionais com o projeto societário hegemônico tem limites numa sociedade capitalista. [...] A construção do projeto ético-político crítico e avançado deve ter em conta tais limites, cujas linhas mais evidentes se expressam nas condições institucionais do mercado de trabalho. (Netto, 1999:6).

Então, os entraves do capitalismo, ou seja tanto o antagonismo entre projeto societário e projeto profissional e o trabalho como uma mercadoria, repercutem na profissão na medida em que esses profissionais encontram dificuldade na execução do seu projeto ético político em seu processo de trabalho, sendo essa a primeira desarticulação que relaciona o objeto de intervenção à Questão Social. Em seguida, 
temos a condição de venda da força de trabalho ${ }^{10}$ como outra forte influência no trabalho dos assistentes sociais, ao falar da profissionalização do Serviço Social Netto escreve:

[...] O que o deslocamento altera visceralmente, concretizando a ruptura, é, objetivamente, a condição do agente e o significado social da sua ação; o agente passa inscrever-se numa condição de assalariamento e a significação social do seu fazer passa a ter um sentido novo na malha da reprodução das relações sociais. Em síntese: é com este giro que o Serviço Social se constitui como profissão, inserindo-se no mercado de trabalho, com todas as consequências daí decorrentes (principalmente com o seu agente tornando-se vendedor da força de trabalho). (Netto, 1996: 69).

Pressupondo que esse modo de produção, ao qual todos os trabalhadores se inscrevem, visa o lucro em todas suas instâncias, essas "consequências decorrentes" sinalizadas por Netto se referem às condições às quais esse trabalho é desenvolvido, seja ela no barateamento de salários ou no próprio meio em que esses trabalhos se inserem. Por isso, tanto a execução do projeto profissional quanto a inserção no mercado de trabalho sofrem por atravessamentos gestados na contradição entre capital e trabalho, ambas expressões geram desarticulações entre o trabalho de gestão institucional e o processo de trabalho do assistente social e apontam para a necessidade de retomar a discussão da identidade profissional (Martinelli 2003).

A discussão a respeito da identidade profissional nos remete a todo o caminhar que gerou a construção do que o Serviço Social é hoje, rompendo com o conservadorismo da prática. $\mathrm{O}$ que aconteceu no processo de atribuição da identidade foi um esforço da burguesia alinhada ao Estado (no passado a tríade composta pela participação da igreja), para definir até onde essa profissão poderia ter "liberdade" de intervir nas expressões da Questão Social.

Dentro de uma democracia burguesa, definiremos essa categoria dentro do que escreve Lênin (1918:1) “A não ser para troçar do senso comum e da história, é claro que não se pode falar de democracia pura enquanto existirem classes diferentes, pode-se

\footnotetext{
${ }^{10}$ Para Marx "Como o de toda outra mercadoria, este valor se determina pela quantidade de trabalho necessário para produzi-la. A força de trabalho de um homem consiste, pura e simplesmente, na sua individualidade viva. Para poder crescer e manter-se, um homem precisa consumir uma determinada quantidade de meios de subsistência, o homem, como a máquina, se gasta e tem que ser substituído por outro homem. Além da soma de artigos de primeira necessidade exigidos para o seu próprio sustento, ele precisa de outra quantidade dos mesmos artigos para criar determinado número de filhos, que hão de substituí-lo no mercado de trabalho e perpetuar a raça dos trabalhadores. Ademais, tem que gastar outra soma de valores no desenvolvimento de sua força de trabalho e na aquisição de uma certa habilidade." $(1865$, p.18)
} 
falar apenas de democracia de classe.”. O autor indica, ao falar de democracia de classes, que essa sempre estará em favor da classe dominante, em consequência disso, as leis e decisões tomadas nessa sociedade são necessariamente de interesse da burguesia. Constantemente os mínimos esforços para barrar o aprofundamento das expressões da questão social, são colocados em discussão, porque são ameaças de uma revolução no horizonte político.

Com base em pesquisa documental, na tentativa de fazer uma aproximação com a memória do Centro Social, foram analisados relatórios de trabalho anuais ${ }^{11}$ da instituição, a partir da análise constatou-se que como objetivos de realização do trabalho havia planejamentos referentes à oferta de atividades relacionadas a orientações sobre higiene básica e cuidados domiciliares.

A partir da aproximação documental, tanto do exemplo mencionado como a outros documentos de trabalho (atas, pesquisas e relatórios) percebe-se que ainda existem fortes indícios de uma identidade atribuída (Martinelli 2003) ao que tange ao Serviço Social nesse espaço sócio ocupacional, podemos vincular esse fenômeno a diversos fatores, sendo eles o próprio histórico de fundação do Centro Social, e os movimentos no interior da profissão pela construção da própria identidade.

Tanto a compreensão da chegada do Serviço Social em tempo integral (2015) quanto o período em que o novo espaço das atividades foi inaugurado (2008) se deram graças a narrativas orais da equipe de trabalho, sobre narrativas orais Martinelli escreve:

[...] Cabe ressaltar que, por meio das narrativas, é possível não só ouvir as falas, mas "escutar" os silêncios, compreender os lampejos da memória. Os sujeitos participantes podem expressar seus pensamentos, suas histórias, experiências, os significados e as memórias sobre as trajetórias profissionais, bem como os contextos históricos relacionados. (Martinelli, 2019:128).

Sem a aproximação desse instrumento seria impossível o entendimento dessas diferentes forças que corroboram para a formação da identidade profissional, essa análise é um dos exemplos de como vem se dando as atividades da instituição. No tópico seguinte será feita uma maior aproximação da intervenção de estágio realizada na cadeira de Estágio em Serviço Social II, onde se deu origem à discussão da identidade profissional nesse campo.

\footnotetext{
${ }^{11}$ São documentos anteriores aos Planos de Ação e indicam o trabalho que objetiva ser desenvolvido ao longo do ano, um planejamento das atividades anuais.
} 


\section{Grupo de Estudos Enquanto Ferramenta Potencializadora da Discussão da Identidade Profissional}

$\mathrm{Na}$ parte final deste estudo, busca-se apresentar o Processo de Trabalho desenvolvido em período de estágio obrigatório, com sinalização do objeto, dos instrumentos e do produto alcançado. No processo interventivo, realizamos uma articulação teórico-prática envolvendo os conhecimentos apreendidos ao longo do processo de formação acadêmica e sua materialização na prática profissional desenvolvida junto ao campo de estágio, através do Projeto de Intervenção "Fortalecimento da identidade do Serviço Social".

As ações interventivas propostas fundamentaram-se no materialismo dialético crítico, paradigma que impulsiona a profissão, tendo como direcionamento as categorias: totalidade, historicidade e contradição. Estas categorias estão intimamente relacionadas ao fazer profissional do/a assistente social. A Totalidade é definida por Costa (2007) como (...) é um instrumento interpretativo que tem a finalidade de compreender as diferenças que compõem uma determinada realidade. Isso significa dizer que o todo está em construção, é inacabado e não está determinado pelas partes, pois a totalidade está sempre em processo de estruturação e desestruturação (2007, p. 56). Essa compreensão está presente na ideia de que essa realidade é dinâmica, e na constante necessidade de estudar a realidade e os meios nos quais se intervém no cotidiano, reconhecendo os processos particulares e sociais envolvidos em determinado contexto social.

Em relação a categoria Historicidade, Costa a define como (...) no método Dialético é onde se encontra a vida dos sujeitos sociais. É na história que o homem existe e se realiza a si mesmo, num processo de construção de sua própria história e de sua humanização, em tempo e no tempo, teleologicamente (Costa, 2007, p.57). Como profissão que intervém nas relações sociais, e ainda, sendo o homem um sujeito histórico, a história é indissociável do trabalho do Serviço Social. Neste sentido, a historicidade foi percebida no campo de estágio no decorrer das intervenções, através dos relatos dos sujeitos participantes do projeto de intervenção. Na mesma esteira de pensamento, Costa também define a categoria Contradição, como:

[...] é reconhecida pela dialética como princípio básico do movimento pelo qual os seres existem. A contradição sempre expressa uma relação de conflito 
no devir do real. Deste modo, cada coisa exige o seu contrário, como determinação e negação do outro. Dessa forma, a transformação somente é possível porque em seu próprio interior coexistem forças que são opostas e buscam constantemente e simultaneamente à unidade e a oposição. (Costa, 2007:54).

As três categorias conceituadas a partir de Costa (2007) remetem ao Serviço Social na medida em que são fundamentais para a existência dessa profissão, a contradição está presente na constituição do próprio objeto profissional, e diz respeito ao embate entre capital e trabalho, gerador das diferentes expressões desse objeto as quais repercutem no cotidiano dos assistentes sociais das mais variadas formas. Essas categorias estão presentes em todo espaço onde o Serviço Social intervém, no Centro Social e Educacional Assunta Marchetti tanto no desenvolvimento do trabalho quanto nas desarticulações desse trabalho, como já antes sinalizado no item anterior acerca do objeto de intervenção deste estudo, que se dá na particularidade das condições da contradição.

O processo de trabalho teve início a partir da identificação das demandas, entendendo-as como uma necessidade da Instituição e posteriormente transformando-a em uma demanda profissional. A alta demanda de trabalho, conjunto a particularidade deste espaço, que possui a desarticulação entre assistente social e o trabalho de gestão, aprofunda a complexidade de realização de ambas as funções, deixando o profissional em uma constante esteira de trabalho e horas extras. A sobrecarga de trabalho não é uma exclusividade desse espaço, na verdade ela se encontra intrínseca à condição de venda da força de trabalho. Esse fator corrobora com o adoecimento destes profissionais, que precisam constantemente correr contra o relógio. Não podemos nos esquecer do contexto ao qual a profissão se insere, de acordo com Vicente,

\footnotetext{
Podemos inferir que também o trabalho de assistentes sociais, como profissão inserida na divisão social, técnica (e sexual) do trabalho, sofre transformações em seu processamento, alterando significados e conteúdo, com consequências deletérias na vida e na saúde de profissionais, em virtude das exigências colocadas no cotidiano da profissão. $\mathrm{O}$ processamento do trabalho de assistentes sociais está se realizando cada vez mais em meio à violência e em condições precárias (de contratos, de salários e de meios) e as queixas de sofrimento têm sido cada vez mais frequentes. (Vicente, 2015:563).
}

Como todo trabalho feito é coordenado contando apenas com o olhar técnico de uma assistente social e realizado pelas mãos de mais de 30 voluntários, levando em consideração as implicações do voluntariado, existem limitações na realização das 
atividades (como a própria execução de um trabalho carregado de intencionalidade). Sobre as implicações do voluntariado, Araújo ressalta os aspectos legais do trabalho voluntário. De acordo com o autor:

O voluntário deve ser considerado pela instituição em que presta seus serviços como um cidadão com direitos e também deveres. Mesmo executando suas tarefas sem requerer nenhum tipo de benefício ou pagamento, possui tanto direitos como responsabilidades, definidos pela instituição e em comum acordo. (Araújo, 2008: 59).

Entende-se que o trabalho voluntário é importante na realização de atividades dentro do Terceiro Setor, mas ele não deve cumprir a exigência de um trabalho profissional. Cabe a necessidade de compreensão sobre cidadania, direitos sociais e políticas sociais, por isso essas ações são um complemento ao trabalho dos assistentes sociais e não devem ser entendidas como um fim em si mesmo.

Existe um caráter paternalista que a instituição adota no seu cotidiano, como ela é mantida por uma congregação de cunho católico, são muitas as práticas de benevolência que se perduram desde sua criação, como a doação de roupas e cestas básicas sem critérios socioeconômicos de avaliação. O público que frequenta o espaço, na sua maioria, não tem os materiais necessários para o trabalho em casa, por essa razão as oficinas têm sido um espaço de convivência comunitária mais do que tem sido um espaço profissionalizante, isso impede a independização dos sujeitos.

Foi observado durante o período em campo da cadeira de estágio I que a intervenção deveria se dar no sentido de planejar as atividades ofertadas, mas conforme a readequação em decorrência do período de 2020/01 (em que se iniciou a quarentena do covid-19) foi feita a intervenção com enfoque na dificuldade que o Serviço Social encontra na instituição quanto a sua própria identidade.

Abordar a discussão da identidade profissional, tendo em vista o objeto dessa intervenção como a desarticulação entre gestão do trabalho e Serviço Social, é coerente em razão de que justamente essa identidade é que permite ao Serviço Social o poder de como e onde agir, é necessário portanto, que para firmar um processo de trabalho conciso, antes de tudo, se firme sua própria identidade. Marx define processo de trabalho como:

Pressupomos o trabalho numa forma em que ele diz respeito unicamente ao homem. Uma aranha executa operações semelhantes às do tecelão, e uma abelha envergonha muitos arquitetos com a estrutura de sua colmeia. Porém, 
o que desde o início distingue o pior arquiteto da melhor abelha é o fato de que o primeiro tem a colmeia em sua mente antes de construí-la com a cera. No final do processo de trabalho, chega-se a um resultado que já estava presente na representação do trabalhador no início do processo, portanto, um resultado que já existia idealmente (Marx, 2013: 255-256).

O objeto de trabalho da intervenção desenvolvida foi o conjunto de desarticulações entre o trabalho de gestão institucional e o processo de trabalho do assistente social no Centro Social. Tendo o objeto profissional como ponto de partida, entendemos essa profissão como aquela que responde às multifacetadas expressões que o modo de produção capitalista condiciona. Assistentes sociais trabalham no enfrentamento e na superação desse sistema produtor de pobreza, exclusão e desigualdade (Iamamoto, 2001).

Com a possibilidade de observar e mais tempo para sistematizar as informações coletadas em período de Estágio I, foi possível ter o entendimento que na verdade tanto a alta demanda de trabalho quanto as desarticulações entre o trabalho de gestão institucional e o processo de trabalho do assistente social oriunda dela, fazem parte de um processo maior de deslegitimação do Serviço Social. Não se pode dizer que essa deslegitimação (da identidade profissional) parta exclusivamente das instituições contratantes ou dos usuários que participam desses serviços, apesar deles estarem sujeitos a reprodução desse ideário.

A aproximação foi feita a partir da utilização do diário de campo, com a intenção de maior aproximação e melhor aproveitamento das informações durante o período de tempo designado ao Estágio curricular, de acordo com Sousa, essa linguagem instrumental:

Trata-se de anotações livres do profissional, individuais, em que o mesmo
sistematiza suas atividades e suas reflexões sobre o cotidiano do seu trabalho.
O diário de campo é importante porque o Assistente Social, na medida em
que vai refletindo sobre o processo, pode perceber onde houve avanços,
recuos, melhorias na qualidade dos serviços, aperfeiçoamento nas
intervenções realizadas - além de ser um instrumento bastante interessante
para a realização de futuras pesquisas. (Sousa, 2008:130).

Além dos diários de campo, a análise institucional foi de suma importância para a realização dessa intervenção, porque permitiu a observação desse processo de trabalho de forma pormenorizada, e possibilitou maior proximidade com a intencionalidade. Sobre a observação Sousa (2008: 126) [...] a observação é o uso dos sentidos humanos para o conhecimento da realidade. Mas não um uso ingênuo dos sentidos, e sim, um uso 
que tem como objetivo produzir um conhecimento sobre a realidade. $\mathrm{O}$ diário de campo e a análise institucional fazem parte do arsenal instrumental dos assistentes sociais e para definir essa categoria Guerra elucida:

\begin{abstract}
Ao alterarem o cotidiano profissional e o cotidiano das classes sociais que demandam a sua intervenção, modificando as condições, os meios e os instrumentos existentes, e os convertendo em condições, meios e instrumentos para o alcance dos objetivos profissionais, os assistentes sociais estão dando instrumentalidade às suas ações. $\mathrm{Na}$ medida em que os profissionais utilizam, criam, adéquam às condições existentes, transformando-as em meios/instrumentos para a objetivação das intencionalidades, suas ações são portadores de instrumentalidade. (Guerra, 2007: 02).
\end{abstract}

Partindo do instrumental profissional, foi usada uma abordagem grupal, para instigar reflexões na equipe técnica do Centro Social. Silva (2017:124) define grupo como: “[...] Se trata de um meio de intervenção social que tem evoluído, em razão da compreensão de que o grupo afeta as atitudes das pessoas que o compõem, pois a diversidade é troca e viabiliza a criação de alternativas conjuntas para se viver de forma plena". E ainda sobre esse tipo de abordagem Pichon define:

\begin{abstract}
Um conjunto de pessoas movidas por necessidades semelhantes e se reúnem em torno de uma tarefa específica, um objetivo mútuo, onde cada participante é diferente e exercita sua fala, sua opinião, seu silêncio, defendendo seu ponto de vista. Os grupos operativos podem ser verticais, horizontais, homogêneos ou heterogêneos, primários ou secundários, porém em todos se observa uma diferenciação progressiva (heterogeneidade adquirida) à medida que aumenta a homogeneidade na tarefa. (Pichon-Rivière,1998:67).
\end{abstract}

É importante ressaltar que essa intervenção também se respaldou nas dimensões do agir profissional. No que se refere à dimensão teórico metodológica, para Gomes (2010, p.15) essa competência é aquela “direcionada a um processo construído a partir do conhecimento que aprendemos durante nosso processo de formação e de prática cotidiana", que é interna à profissão. O próprio grupo de estudos é um exemplo do uso dessa competência, pois a intervenção se pautou na leitura de materiais que embasassem teoricamente o estudo da identidade profissional, ela também é indispensável fora desse contexto, porque para uma profissão de bases sólidas e preparo para intervir nas diferentes faces da Questão Social que se apresentam, há que se recorrer a um arsenal teórico. 
Lembremos que nenhuma das dimensões profissionais anda sozinha e que se orientam na complementaridade entre si, representando as competências, habilidades e atitudes profissionais.

Pensando no agir profissional, lembremos que a dimensão técnico-operativa, conforme afirma Gomes (2010:31) ao abordarmos estamos "nos referindo aos meios de trabalho adotados pelos profissionais na sua prática, ou seja, a habilidade de colocar o conhecimento em ação" ou seja, ela diz respeito à maneira como realizamos as nossas ações profissionais, como colocamos em prática os conhecimentos adquiridos ao longo da nossa formação.

Usando esse instrumento e articulando as diferentes dimensões profissionais foi possível dialogar sobre as discussões relacionadas ao fortalecimento da identidade com todos os participantes do grupo de uma maneira que fosse possível um maior compartilhamento de ideias. Portanto a intervenção se deu a partir de um grupo de estudos com a equipe técnica, como potencializador da discussão da identidade profissional nesse espaço sócio ocupacional.

No âmbito da dimensão ético política, a construção metodológica da intervenção esteve pautada nos princípios do Código de Ética da Profissão, e essa dimensão está presente, como as competências anteriores, em todo trabalho profissional, seja na defesa intransigente dos direitos humanos ou nas próprias atribuições profissionais, discussões essas contidas nos materiais aos quais essa intervenção se propôs a abordar.

A equipe técnica do Centro Social é composta pela assistente social e estagiários curriculares, a intervenção contou com a presença de três estagiárias curriculares que estavam em campo no período da realização da intervenção além da assistente social supervisora de campo. A intervenção foi realizada presencialmente, foram feitos 7 encontros de 1 hora cada, os encontros foram feitos uma vez na semana e por isso a intervenção foi realizada no período de 1 mês.

Apesar da duração dos encontros ser de 1 hora, as leituras eram feitas em conjunto por conta da disponibilidade dos participantes, logo após as leituras o grupo discutia as impressões sobre o texto, e eram por mim guiados a partir das ideias principais dos textos selecionados.

O objetivo geral que buscou-se alcançar, a partir da materialização das ações interventivas, consistiu em fortalecer a identidade e o exercício profissional da equipe técnica da instituição Centro Social e Educacional Assunta Marchetti quanto ao seu 
processo de trabalho. Quanto aos objetivos específicos, buscou-se auxiliar os profissionais da equipe técnica a refletirem sobre as demandas do Centro Social; refletir sobre o instrumento formação continuada como estratégia metodológica a ser usada no Centro Social; criar um espaço de discussão com a equipe técnica para repensar práticas ligadas a gestão e planejamento.

A proposta era que durante a intervenção o conteúdo abordado começasse a discussão sobre os fundamentos do Serviço Social, a discussão foi feita a partir do texto "Serviço Social, História e Desafios" de Maria Carmelita Yazbek. É indispensável pensarmos na história profissional para fazermos a discussão das diferentes identidades, atribuída e construída, conforme amplamente discutido nesse artigo (Martinelli 2003).

Ao longo da leitura desse texto, o grupo salientou expressivamente a problemática do adoecimento da categoria profissional frente a alta demanda de trabalho e por vezes a insalubridade deste (Diário de Campo, 2020). Sobre o desgaste gerado pelo trabalho

\footnotetext{
Nas interseções entre processo de trabalho e processo saúde-doença, determinações de ordem sociopolítica e econômica passam a atuar. Nas situações de trabalho dominado, a desvantagem que faz com que o corpo e os potenciais psíquicos do trabalhador sejam consumidos pelo processo de trabalho e por constrangimentos a ele vinculados se configura como desgaste. (Seligmann-Silva, 2011: 135).
}

Com adequação do tema do segundo encontro, foi discutido sobre a precarização do trabalho e seus impactos na categoria profissional, e nesse momento outra categoria que se sucedeu foi a jornada de trabalho feminina (Diário de Campo, 2020). Nas palavras de Cisne

\footnotetext{
Dentro de uma perspectiva crítica, sabe-se que a responsabilidade com a reprodução cabe ao Estado, no entanto, como já apontado, grande parte dela é imputada às mulheres. Isso exige lutas políticas para exigir, fundamentalmente, do Estado o cumprimento de suas obrigações, inclusive para banir ou, por outra, mitigar a "dupla" e muitas vezes "tripla" jornada de trabalho. (Cisne 2004:161).
}

Visto que majoritariamente a profissão é formada por mulheres, existem muitas questões que perpassam a vida dos assistentes sociais, nesse momento o grupo pode passar a se perceber dentro de um sistema de opressão também. Não é por acaso que a profissão é tomada como "ajuda" ou "cuidado", na verdade esse legado se relaciona diretamente com a relação de "feminino" dessa sociedade. 
No terceiro encontro, quando o intuito foi discutir novos paradigmas da gestão, a partir do texto "Tendências da Gestão Social" de Ladislau Dowbor, levando em consideração que a gestão também é tema que atravessa o trabalho profissional do Serviço Social na instituição. Gestão social é, nas palavras de Carvalho (1999:.4) “ a gestão das ações sociais públicas. A gestão do social é, em realidade, a gestão das demandas e necessidades dos cidadãos.". Esse texto suscitou que se comentasse sobre o "valor" da vida no capitalismo (Diário de Campo, 2020)

No quarto encontro, foi falado sobre o caminhar da assistência social, onde foi discutida a desqualificação profissional a partir do voluntariado, Machado descreve,

\footnotetext{
Não há como negar o que a realidade nos impõe enquanto trabalhador assalariado; de modo que é necessário estarmos atentos aos inúmeros assistentes sociais e estagiários inseridos nas ONGs, que precisam de maior proximidade com o debate acadêmico, com a análise da realidade do cotidiano institucional, pois a questão social se enfrenta com teoria e não com trabalho voluntário. (Machado (2010: 270).
}

A autora citada dialoga no sentido de valorização e qualificação profissional, neste momento abrindo precedentes para a discussão da identidade profissional. No quinto encontro, partindo da trajetória de vida particular de cada membro participante da intervenção é que foi possível debater como se forma uma identidade, trazendo a categoria identidade do individual ao coletivo (Diário de Campo, 2020). Novamente Martinelli (2003:146) nos lembra que, "mais do que perguntar por identidade devemos nos perguntar por identidades, por processos de identificação em curso, pois as identidades são, fundamentalmente, condição de ser e possibilidade, são permanências, e são transformações".

No último encontro também foi feita a entrega do produto materializado da intervenção, um marca páginas de título "Serviço Social é" contendo algumas informações sobre a identidade profissional. De acordo com os objetivos gerais e específicos, tanto a iniciativa de discutir a identidade profissional quanto uma maior aproximação de capacitações continuadas e das demandas do Centro Social, foram redimensionadas na construção coletiva de um material distribuído aos participantes da intervenção, é importante ressaltar que essa materialização é somente um instrumento que condensa os assuntos abordados, o próprio grupo de estudos se caracteriza como um instrumento potencializador da continuidade dessa discussão dentro desse espaço. 
A partir do entendimento de que a questão da identidade é uma contínua apropriação do próprio desenvolvimento do processo de trabalho do Serviço Social do Centro Social, é que podemos discutir a capacitação continuada como meio de reafirmar a categoria da identidade, de acordo com trecho da avaliação da intervenção foi possível perceber que o grupo manifestou desejo de continuidade das atividades, "Foi de grande valia, pois me abriu o horizonte de conhecimento, aprendi muito sobre identidade profissional. Gostaria que tivesse mais reuniões sobre o assunto. Muito bom.” (Diário de Campo, 2020).

No que tange à avaliação do alcance dos objetivos previstos pelo Projeto de Intervenção, acredita-se que os resultados alcançados são coerentes ao proposto pelos objetivos, uma vez que a intenção de abrir caminho para a discussão sobre o trabalho profissional foi iniciada nesse espaço e a equipe técnica se aproximou do instrumento grupo de estudos como potencializador do estudo sobre a identidade profissional. É necessário destacar que o objeto de intervenção, as desarticulações do processo de trabalho, não se rearticulam a partir de uma intervenção partida de um Estágio Obrigatório em Serviço Social, na verdade essa condição é intrínseca a existência da contradição, por isso, como antes mencionado, é um trabalho contínuo de reafirmação enquanto profissão.

\section{Considerações Finais}

Ao chegar no final deste estudo, considera-se o quanto ele foi importante tanto profissional quanto pessoal, permitindo aprimorar os conhecimentos. O processo de aprendizagem proporcionou viver a práxis do Serviço Social. A construção deste artigo partiu das experiências vivenciadas em Estágio Obrigatório e da pesquisa documental sobre a memória do Centro Social e Educacional Assunta Marchetti. Foram usadas a análise institucional, o relatório de estágio obrigatório e o projeto de intervenção na organização de informações presentes nesse artigo, bem como uma pesquisa bibliográfica sobre as categorias que se sobressaíram na construção deste trabalho, os aportes teóricos utilizados neste estudo permitiram dar visibilidade ao tema. As categorias do método dialético crítico contribuíram para desvelar a realidade, enquanto os aportes técnico-operativos utilizados na intervenção, em especial, o grupo de estudos, permitiu a discussão sobre identidade profissional. 
O objetivo escolhido neste trabalho de conclusão foi refletir sobre a identidade profissional no processo de trabalho do assistente social, vivenciado durante o estágio obrigatório no Serviço Social. Tendo em vista as medidas de segurança necessárias para lidar com a pandemia do COVID-19, o acesso a informações necessárias para a construção desse artigo, presentes no campo de Estágio Obrigatório, foram de difícil acesso, esse processo se consistiu em um grande desafio. $\mathrm{O}$ processo metodológico foi pensado de forma a contemplar os objetivos deste estudo e a execução do projeto de intervenção permitiu que fosse feita uma observação empírica das categorias estudadas ao longo da formação em Serviço Social.

A partir desse objetivo, foi traçado o caminhar conceitual sobre Terceiro Setor, Questão Social e Políticas Sociais, para fazer uma aproximação das categorias presentes no campo onde foi realizado o Estágio Obrigatório, e por fim a apresentação do projeto de intervenção.

A identidade profissional foi amplamente discutida ao longo desse trabalho e também abordada durante o período de intervenção, procurou-se dar visibilidade a temática em questão, dada a sua relevância ao processo de trabalho do Serviço Social na medida em que passa a se tornar necessário reafirmar a Identidade Construída perante as reorganizações do capital nas suas tentativas de perpetuar-se enquanto modelo de sociedade, não distante do que constata Martinelli:

\footnotetext{
A tarefa assumida pela sociedade de organização da caridade - racionalizar a assistência e reorganizá-la em bases científicas - acabou constituindo, na verdade, uma estratégia política através da qual a burguesia procurava desenvolver o seu projeto de hegemonia de classe [...] a assistência posicionava-se como um, entre outros, mecanismos associados ao Estado burguês para garantir a expansão do capital. (Martinelli, 2003: 100).
}

Dada a continuidade das forças do capital em proteger seus interesses de classe, nas suas diferentes formas de reafirmar identidades e despolitizar categorias, procurouse dar visibilidade a temática em questão, sua relevância continua em evidência no cenário atual, com isso esse artigo procura abordar a discussão tecendo considerações que permitem entender como se orientam na atualidade as marcas de uma identidade atribuída.

O diálogo com a memória oportunizou melhor compreensão sobre a história da instituição e a sua interface com a identidade profissional. Uma forma de recomposição 
do passado e suas transformações, relacionando-as a trajetória do SS e a identidade profissional.

As desarticulações presentes no processo de trabalho, que foram identificadas ao longo do Estágio Obrigatório, são na realidade uma consequência da exploração do trabalho e dos antagonismos entre o projeto dessa sociedade e o projeto político profissional, podem por isso se apresentar em qualquer campo onde se insira o Serviço Social, e é a partir disso que se torna relevante discutir a identidade profissional em um processo contínuo de reafirmação.

Essa discussão se tornou possível através da reflexão das categorias do método dialético crítico aprendidas ao longo da formação em Serviço Social, bem como das dimensões do agir profissional que estiveram presentes na realização da intervenção, que foi parte significativa na organização das ideias presentes neste trabalho de conclusão, e na pesquisa bibliográfica de autores do Serviço Social.

Enquanto reflexão sobre as ideias expostas nesse trabalho, a reafirmação da identidade pode encontrar espaço através de um estudo contínuo que extrapola a compreensão de estudo formal e acadêmico, sem que haja um rompimento com a intencionalidade e com o compromisso de classe, como parte significativa do trabalho profissional, uma apreensão contínua da dimensão teórico metodológica. É importante mencionar que valorizar essa dimensão não significa valorizá-la em detrimento das outras, mas entender sua importância em meio ao processo de trabalho. A identidade construída caminha ao lado dos conhecimentos que essa profissão produz, nesse sentido a criação e a apreensão de novos conhecimentos é uma reafirmação.

\section{Referências}

ANDRADE, Renato de. Serviço Social, Gestão e Terceiro Setor, Dilemas nas políticas sociais. São Paulo, Saraiva, 2015.

ARAÚJO, Jairo. Melo. Voluntariado: na contramão dos direitos sociais. São Paulo: Cortez, 2008.

BENJAMIN, Walter. Sobre o conceito de história [recurso eletrônico]: edição crítica / Walter Benjamin; organização e tradução Adalberto Müller, [notas] Márcio SeligmannSilva. - 1. ed. - São Paulo: Alameda. 2020.

BRASIL. Lei 8.662/93 de regulamentação da profissão. 10a . ed. rev. e atual. 
BRASÍLIA: Conselho Federal de Serviço Social, 2012.

BEHRING, Elaine Rossetti. Políticas Sociais, Fundamentos e História. 6 ed. São Paulo: Cortez. 2009.

BETTANZOS, Luiza Vitória Comerlato. Histórico Centro Social. Canoas, 2020.

BETTANZOS, Luiza Vitória Comerlato; Diário de Campo. Canoas 2020.

CARVALHO, Maria do Carmo Brant. Gestão Social: alguns apontamentos para o debate. 1999.

CFESS. Código de Ética Profissional do Assistente Social. Brasília: CFESS, 1993.

CISNE, M. Serviço Social: Uma Profissão De Mulheres Para Mulheres? Recife, 2004.

COSTA, Ruthe Corrêa da. A terceira idade hoje sob a ótica do Serviço Social. Canoas: Editora Ulbra, 2007.

COSTA, Selma Frossard. Serviço Social e o Terceiro Setor. In: Revista Integração (eletrônica), CETS/FGV SP, novembro de 2003.

FISCHER, Rosa Maria. O desafio da colaboração: práticas de responsabilidade social entre empresas e terceiro setor. São Paulo: Editora Gente, 2002.

FRANCO, Rolando. Lineamentos para una política social orientada a superar la crisis. Paraguaya de Sociologia. Assunção, n. 73, 1988.

GIL, Antônio Carlos. Como elaborar projetos de pesquisa. $5^{\mathrm{a}}$ Ed. São Paulo: Atlas,2010.

GOMES, Maria Suzete Muller Lopes Keline; SANGHI, Simone. Competência TécnicoOperativa em Serviço Social. Canoas. ULBRA. 2010.

HALBWACHS, Maurice. A Memória Coletiva. Tradução de Laurent Léon Schaffter do original La Mémoire Collective. Presses Universitaires de France, Paris, p. 25 - 47. 1990.

IAMAMOTO, Marilda. Villela.; CARVALHO, Raul de. Relações Sociais e Serviço Social no Brasil: esboço de uma interpretação histórico-metodológica. São Paulo, Cortez, 1983.

IAMAMOTO, Marilda. Villela. Questão social no capitalismo. Revista da Associação Brasileira de Ensino e Pesquisa em Serviço Social - ABEPSS, 3. Rio de Janeiro: Ed. Grafine, jan - jun 2001.

MACHADO, Graziela Scheffer. O Serviço Social nas ONGs no campo da saúde: projetos societários em disputa. Ser. Soc. Soc. Jun 2010. Disponível em: https://doi.org/10.1590/S0101-66282010000200005 acesso em 31/mai/2021. 
MARTINS, José de Souza. Sobre o modo capitalista de pensar. São Paulo: Hucitec, Coleção Ciências Sociais, Série Linhas de Frente, 1978.

MARX, Karl. Salário Preço e Lucro. Ediciones en Lenguas Extranjeras, 1953 Moscou.

MARX, Karl. O capital: crítica da economia política: Livro I: o processo de produção do capital. São Paulo: Boitempo, 2013.

MARX, Karl. O Manifesto do Partido Comunista. 6a ed. Petrópolis: Vozes, 1996.

MARX, Karl. A ideologia Alemã. São Paulo: Boitempo, 2007

MARTINELLI, Maria Lúcia. A Pergunta pela Identidade Profissional do Serviço Social: Uma Matriz de Análise, Serv. Soc. \& Saúde, Campinas, SP v. 12, n (1), p. 145156, 2013.

MARTINELli, Maria Lúcia. Serviço Social Identidade e Alienação. $8^{a}$ ed. São Paulo: Cortez. 2003.

MARTINELLI, Maria Lúcia. A história oral na pesquisa em serviço social: da palavra ao texto. São Paulo: Cortez, 2019.

MINAYO, Cecília de Souza. (org); DESLANDES, Suely Ferreira. Pesquisa Social: teoria, método e criatividade. 29. Ed. - Petrópolis, RJ: Vozes, 2010.

NETTO, José Paulo. A Construção do Projeto Ético-Político do Serviço Social. Capacitação em Serviço Social e Política Social. Brasília, 1999.

NETTO, José Paulo. Capitalismo Monopolista e Serviço Social. 2. ed. São Paulo: Cortez, 1996.

PICHON-RIVIÉRE, Enrique. O Processo Grupal. Tradução: Marco Aurélio de Velloso; Revisão: Mônica Stahel, 6. ed. São Paulo: Martins Fontes, 1998.

SILVA, Ângela Maria Pereira da. Instrumentalidade e Instrumentais técnicos do Serviço Social. Curitiba: InterSaberes, 2017.

SELIGMANN-SILVA. Edith. Trabalho e desgaste mental: o direito de ser dono de si mesmo. São Paulo: Cortez, 2011.

SOUSA, Charles Toniolo de. A prática do assistente social: conhecimento, instrumentalidade e intervenção profissional. Emancipação, Ponta Grossa, 119-132, 2008.

VICENTE, Damares. Desgaste mental de assistentes sociais: um estudo na área da habitação. Serv. Soc. Soc. Jul-Sep 2015. Disponível em: https://doi.org/10.1590/01016628.037 acesso em 31/mai/2021. 
Cidades em metamorfose: memórias, percursos urbanos e imagens

Data de submissão: 15 de julho de 2020

Data de publicação: 20 de dezembro de 2021 